\title{
IncRNA AFAP1-AS1 Promotes Migration and Invasion of Non-Small Cell Lung Cancer via Up-Regulating IRF7 and the RIG-I-Like Receptor Signaling Pathway
}

\author{
Xiao-Di Tang ${ }^{a} \quad$ Duo-Duo Zhang $^{\mathrm{a}} \quad$ Linpei Jia $^{\mathrm{b}} \quad$ Wei Jic Yu-Shuang Zhao ${ }^{\mathrm{d}}$ \\ aDepartment of Radiation Oncology, China-Japan Union Hospital of Jilin University, Changchun, \\ bDepartment of Nephrology, Xuanwu Hospital, Capital Medical University, Beijing, 'Department of \\ Vascular Surgery, Jilin Provincial People's Hospital, Changchun, dDepartment of Outpatient, China-Japan \\ Union Hospital of Jilin University, Changchun, China
}

\section{Key Words}

IncRNA • AFAP1-AS1 • IRF7 • Non-small cell lung cancer $\bullet$ RIG-I-like receptor signaling pathway

\begin{abstract}
Background/Aims: Accumulating evidence has highlighted the importance of long noncoding RNAs (IncRNAs) as competing endogenous RNAs (ceRNAs) in tumor biology. Among others, actin filament-associated protein 1 antisense RNA 1 (AFAP1-AS1) has been associated with non-small cell lung cancer (NSCLC). However, it remains unclear how AFAP1-AS1 participates in the development and progression of NSCLC. Methods: The peripheral blood samples were collected from patients with NSCLC. White blood cell subsets were classified and levels of interleukin (IL)-10, IL-12 and IFN- $\gamma$ in serum were measured. We then identified its target gene of AFAP1-AS1 via bioinformatics methods. NSCLC cell line with the highest expression of AFAP1-AS1, i.e. H1975 was selected for in vitro experiments. A series of inhibitor, vector and siRNA were employed to validate the regulatory mechanisms of AFAP1-AS1 in the development and progression of NSCLC. Cell proliferation was detected by MTT assay and EdU staining. Cell migration and invasion, and cell cycle and apoptosis were measured by transwell assay and flow cytometry, respectively. Results: A high expression of AFAP1-AS1 was identified in NSCLC, alongside with a reduced level of IL-12 and increased levels of IL-10 and interferon (IFN) $-\gamma$. Aberrant expressions of AFAP1-AS1 were associated with pathological grade, TNM staging and metastatic potential of NSCLC. AFAP1-AS1 could activate interferon regulatory factor (IRF)7, the retinoid-inducible protein (RIG)-I-like receptor signaling pathway and $\mathrm{BCl}-2$ in vitro. Over-expression of AFAP1-AS1 promoted NSCLC cell proliferation, invasion and migration while inhibiting cell apoptosis. Conclusion: IncRNA AFAP1-AS1 promotes migration and invasion of non-small cell lung cancer via up-regulating IRF7 and the RIG-I-like receptor signaling pathway.




\section{Introduction}

Lung cancer remains one of the most frequent and most deadly tumor entities, with 1.6 million tumor-related deaths annually worldwide [1]. Lung cancer comprises small cell lung cancer (SCLC), which accounts for approximately 15\% of all lung cancers and non-small cell lung cancer (NSCLC), which accounts for approximately 85\% [2]. Despite the progress in lung cancer diagnostics in recent decades, most patients with NSCLC are diagnosed at an advanced stage [3]. Survival of NSCLC remains disappointing with a 5-year survival of $18 \%$ for all NSCLC patients, and a 60\%-80\% survival in stage I patients after an anatomical resection. Although advances in treatments have resulted in an increased survival rate and knowledge of lung cancer biology has much improved, the prognosis of lung cancer still remains poor [4]. Poor prognosis of NSCLC is associated with lack of early diagnostic biomarkers and high potentials of invasion and metastasis. In this regard, development of molecular testing to identify an increasing number of potentially clinically actionable genetic variants by using smaller samples obtained is an urgent need [5].

Over the past decade, genome-wide transcriptomic analyses have clarified that mammal genome produces many long transcripts, namely long non-coding RNAs (lnc-RNAs) [6]. IncRNAs are a class of long non-protein coding RNAs greater than 200 nucleotides, mainly transcribed by RNA polymerase II from intergenic regions, promoter regions, or by transcriptional active pseudogenes [7]. IncRNAs may undergo post transcriptional processing, including $5^{\prime}$ capping, alternative splicing, RNA editing, and polyadenylation as protein coding genes do [7]. Currently, IncRNAs can be divided into five subgroups including sense, antisense, bidirectional, intronic, and intergenic [https://www.ncbi.nlm.nih.gov/ pmc/articles/PMC4278269]. The regulation of protein-coding genes expression is the most important function among the various ones performed by lncRNA. However, others functions like epigenetic regulation, alternative splicing, RNA maturation and transport, protein synthesis, modulation of protein activity, and alternation of protein localization, as well as being precursors of small RNAs and tools for silencing microRNAs, have been well documented [7].

Importantly, IncRNAs are involved in the cell cycle regulation, survival, migration, and metabolism, and their dysregulation appears to contribute to the developmentand progression of human cancer [8]. IncRNAs play active roles in modulating the cancer epigenome and may be important targets for cancer diagnosis and therapy [8]. The human genome contains many thousands of IncRNAs. Recent studies have also shown that most lncRNAs displayed tissue-specific expression patterns [7].

Identification of NSCLC associated IncRNAs and the investigation of their molecular and biological functions are vital. IncRNAs have been associated with lung cancer [9]. Among other, actin filament-associated protein 1 antisense RNA 1 (AFAP1-AS1), a wellknown lncRNA that is over-expressed in various tumor tissues and cell lines, is closely associated with poor outcome of human cancers including lung cancer [10]. In particular, AFAP1-AS1 was significantly up-regulated in lung cancer associated with poor prognosis [11]. In vitro experiments demonstrated that AFAP1-AS1 knock-down significantly inhibited the invasive and migration capability of lung cancer cells [11]. In a recent study, AFAP1-AS1 was further found up-regulated in NSCLC [12]. However, the exact mechanism of AFAP1-AS1 in NSCLC still remains unclear. In this study, we aim to investigate the expressions of AFAP1AS1 in NSCLC and its role in the development and progression of NSCLC. 


\section{Cellular Physiology Cell Physiol Biochem 2018;50:179-195 \begin{tabular}{l|l} 
and Biochemistry Published online: 3 October 2018 & $\begin{array}{l}\text { D } 2018 \text { The Author(s). Published by S. Karger AG, Basel } \\
\text { www.karger.com/cpb }\end{array}$
\end{tabular}}

Tang et al.: AFAP1-AS1 in NSCLC

\section{Materials and Methods}

\section{Ethical statement}

The study protocol was approved by the Committee on the Ethics of China-Japan Union Hospital of Jilin University and informed consent was obtained from each participant.

\section{Patients and sampling}

One hundred and 65 patients with NSCLC (119 males and 46 females) with an average age of 60.3 years, 118 patients with benign lung tumor (85 male and 33 females) with an average age of 58.2 years, and 173 healthy subjects (124 male and 49 female) with an average age of 57.7 years were enrolled from the China-Japan Union Hospital of Jilin University between September 2013 and February 2017. Patients diagnosed with NSCLC were included if they met the following criteria: were diagnosed with NSCLC and had not diagnosed with any tumor before; received no anti-tumor treatment after diagnosis; had indications of surgical resection and had been confirmed by pathological examination after operation; and patients' expected survival time was more than 12 months. Excluding criteria were as follows: patients had abnormal functions of heart, lung and kidney; or severe complications occurred during or after the operation.

\section{ELISA}

IL-10, IL-12, and IFN- $\gamma$ and swere detected according to instructions of ELISA kit manufacturers (human IL-10 ELISA kit, NO: 55R-1622, Dakewe Biotech Company, China; human IL-12 ELISA kit, Westang Biotech Company, China; human IFN- $\gamma$ ELISA kit, NO: EK0373, Yuhengfeng Biotech Company, China). Briefly, monoclonal antibodies were coated onto standard ELISA plates (Nalge Nunc, Denmark) in a volume of $100 \mu \mathrm{l} /$ well overnight at $4^{\circ} \mathrm{C}$. After three washings with phosphate-buffered saline (PBS), uncoated sites

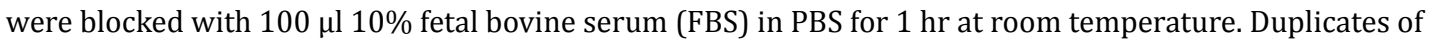
samples or recombinant standards were added and the plates were incubated for $1 \mathrm{hr}$ at room temperature. After washing, the plates were incubated with biotinylated detecting antibody against IL-10, IL-12, and IFN- $\gamma$ (eBioscience, US), respectively, for $2 \mathrm{hrs}$ at room temperature. Then avidin-conjugated horseradish peroxidase (HRP, eBioscience, US) was added for $30 \mathrm{~min}$. Color reaction was performed with $100 \mu \mathrm{l}$ of tetramethylbenzidine (TMB, Sigma-Aldrich. US) for $30 \mathrm{~min}$ and the reaction was terminated by adding $2 \mathrm{M}$ sulfuric acid (Sigma-Aldrich, US). The plates were immediately read at $450 \mathrm{~nm}$ with an ELISA reader (Tecan, Switzerland). The concentrations of proteins were quantified by extrapolation from the standard curve.

\section{Flow cytometry}

Peripheral blood regulatory T cells (Treg), Th1, Th2, dendritic cells (DC) and other immune cell subsets were detected using flow cytometry. FITC-, PE-, APC- and PerCP-conjugated antibodies were purchased from commercial suppliers. Specifically, anti-mouse-CD1a, CD3, CD4, CD8, CD19, CD20, CD25, CD16/32, CD45, CD 80, CD 83, CD86, NK1.1, dendritic cell marker, T cell receptor (TCR), B cell receptor (BCR), IL-2, IL-4, IL-6, IL-10, IL-12, IL-13, IL-17A, IL-17F, IFN- $\gamma$, TGF- $\beta$, TNF- $\alpha$ monoclonal antibodies, and mouse-FoxP3 staining set were from eBioscience, US; and anti-mouse-CD45 monoclonal antibodies were from BD Biosciences (US). Cells were harvested and washed with 1\% bovine serum albumin (BSA, Sigma-Aldrich, US) in PBS. For staining of molecules with extracellular expression, cells were incubated with FITC-, PE-, APC, and/ or PerCP-conjugated antibodies for $15 \mathrm{~min}$ at room temperature. The staining of FoxP3 was according to instructions provided by the manufacturer. For staining of other molecules with intracellular expression, cells were fixed with 2\% paraformaldehyde (Merck, US) for $15 \mathrm{~min}$ at room temperature and permeabilized with $0.5 \%$ freshly prepared saponin (Sigma-Aldrich, US) in PBS containing 1\% BSA. The permeabilized cells were incubated with FITC-, PE-, APC, and/or PerCP-conjugated antibodies for 15 min at room temperature. FITC-, PE-, APC- and PerCP-conjugated isotype antibodies (all from BD Biosciences, US) were used as negative controls. Cells were washed twice, resuspended in $1 \%$ paraformaldehyde in PBS and stored at $4^{\circ} \mathrm{C}$ until flow cytometric analysis with an FACSCanto ${ }^{\mathrm{TM}}$ II cytometer (Becton Dickinson, US) using the FACSDiva software (Becton Dickinson, US). Surface and intracellular molecule expressions were assessed by determining the positive cell percentage. In each experiment, cells from all groups were collected and analyzed at each time point on the same day with the same cytometer settings. Flow cytometric data were analyzed with the CellQuest Pro software (Becton Dickinson, US). 


\section{Cellular Physiology Cell Physiol Biochem 2018;50:179-195 \\ \begin{tabular}{l|l|l} 
and Biochemistry Published 10.1159/000493967 & $\begin{array}{l}\text { D } 2018 \text { The Author(s). Published by S. Karger AG, Basel } \\
\text { www.karger.com/cpb }\end{array}$
\end{tabular}}

Tang et al.: AFAP1-AS1 in NSCLC

Flow cytometry was also used to detect cell apoptosis. According to the instructions of the annexinV-FITC apoptosis kit manufacturer (Shanghai Yeasen Biotechnology Co., Ltd., China), annexin-V-FITC, propidiom iodide (PI), and HEPES were blended at a ratio of 1: 2: 50 to make annexin-V-FITC/PI dye liquor. $100 \mu \mathrm{L}$ dye liquor was used to re-suspend $1 \times 10^{6}$ cells and then the mixture was incubated for $15 \mathrm{~min}$ at room temperature. Then $1 \mathrm{~mL}$ HEPES was added. To determine cell apoptosis, the FITC/PI fluorescence was detected through a $525 \mathrm{~nm}$ and $620 \mathrm{~nm}$ bandpass filter and $488 \mathrm{~nm}$ excitation. Annexin $\mathrm{V}^{+} \mathrm{PI}^{-}$cells represent apoptotic cells.

\section{Bioinformatics prediction}

The NSCLC related expression profiles (GSE33532) and annotated probe files were downloaded from retrieving GEO database (http://www.ncbi.nlm.nih.gov/geo) and detected by Affymetrix Human Genome U133 Plus 2.0 Array. The Affy installation package of R software was performed for the background correction and normalization of each profile data [13]. Then, the linear model in the limma installation package-empirical Bayesian statistics combined with the traditional $t$-test to perform nonspecific filtering of the expression data to screen out differentially expressed lncRNA [14]. Multi Experiment Matrix website (MEM, http://biit.cs.ut.ee/mem/) was used to predict differentially expressed IncRNA, which is a web based tool for performing co-expression queries over large collections of gene expression experiments, and provided access to several hundreds of publicly available gene expression datasets of different tissues, diseases and conditions, arranged by the species and microarray platform types [15]. The Web Gestalt database (http://www.webgestalt.org) was used to enrich and analyze the target gene of KEGG to determine the most important biochemical pathways and signaling pathways [16].

Construction of AFAP1-AS1 vector and siRNA-induced RNA interference

Based on the transcriptional sequence of the AFAP1-AS1 gene in GenBank and online design software, the AFAP1-AS1 gene, siRNA sequence (design 3 pairs of siRNA sequences for each gene) and negative control sequence were designed as follows: siRNA-1: GCACACGGCTTATAATTAA; siRNA-2: CCTGATACATTCAGGAAAT; siRNA-3: GCCACTTGCTTGTCTGCAT; siRNA-NC: ACCUCUUGCAUTGCTGGUA (synthetized by Genechem genetic biology Company, China). The correct sequence of synthesis was cloned into the plasmid vector pcDNA3.1 (Invitrogen, US) with Hind III and XHo I restriction sites at $16^{\circ} \mathrm{C}$ for $1 \mathrm{hr}$ and conversion of the product into the receptive Escherichia Coli DH5 $\alpha$ (D9052, Takara, US), then screened by colony PCR identification of resistant colonies and positive clones were sequenced. Plasmids were extracted and stored at $-20^{\circ} \mathrm{C}$.

\section{Cell culture and transfection}

NSCLC cell lines A549, H1975, H1650, H1395 and H12994 were obtained by courtesy of the Chinese Academy of Science. Cells were cultured in M199 culture medium containing $10 \%$ serum at $37^{\circ} \mathrm{C}$ with $5 \% \mathrm{CO}_{2}$. The cell line with the highest expression of AFAP1-AS1, i.e. H1975 was selected for subsequent experiments. Cells were divided into 6 groups, including the blank (no plasmids were transfected), negative control (NC, transfected with negative control plasmid), AFAP1-AS1 vector (transfected with AFAP1-AS1 over-expression plasmid), siRNA-AFAP1-AS1 (transfected with siRNA-AFAP1-AS1 interference plasmid), RIG-I-like receptor inhibitor (treated with RNF5, an ubiquitin ligase that down-regulates the RIG-I-like receptor signaling pathway [17]) and AFAP1-AS1 vector+ RIG-I-like receptor inhibitor (RNF5) groups. Cells were cultured and used for further experiments when they reached 80\% confluency. $200 \mu \mathrm{L}$ serum-free medium Opti-MEM (Thermo Fisher, US) was used to dilute $6 \mu$ L lipofectamin 2000 (Invitrogen, US) and 100 $\mu \mathrm{L}$ serum-free Opti-MEM medium to dilute $2 \mu \mathrm{g}$ plasmids. The solutions were then mixed and incubated for $20 \mathrm{~min}$ at room temperature. Each culture hole was added with $180 \mu \mathrm{L}$ Opti-MEM medium, and then the transfection compound was added. After $48 \mathrm{hr}$ culture at $37^{\circ} \mathrm{C}$ with $5 \% \mathrm{CO}_{2}$, cells were harvested and the transfection effect was evaluated by RT-qPCR.

Reverse transcription quantitative polymerase chain reaction (RT-qPCR)

The total RNAs were extracted in strict accordance with the instructions from the manufacturer for the Trizol kit (Invitrogen, US), and the concentration and purity of RNAs were determined by the Trizol kit as a template as well. All the primers used in this study were synthesized by Takara Biotechnology Ltd., China (Table 1). Reverse transcription was performed by cDNA reverse transcription system (Beijing Reanta 


\section{Cellular Physiology Cell Physiol Biochem 2018;50:179-195 \begin{tabular}{ll|l} 
DOI: 10.1159/000493967 & Ond Biochemistry 2018 The Author(s). Published by S. Karger AG, Basel \\
wublished onlarger.com/cpb
\end{tabular} \\ Tang et al.: AFAP1-AS1 in NSCLC}

Company, China), with the reaction condition set as $30-50 \mathrm{~min}$ at $42^{\circ} \mathrm{C}$ and $5 \mathrm{sec}$ at $85^{\circ} \mathrm{C}$. The obtained cDNA was diluted to $50 \mathrm{ng} / \mu \mathrm{L}$ and each $2 \mu \mathrm{L}$ was used for $25 \mu \mathrm{L}$ of amplification system. RT-qPCR then was carried out with $2 \mu \mathrm{g}$ cDNA as the templet using the fluorescence quantitative PCR instrument (Daan Gene Co., Ltd., China). The reaction conditions consisted of pre-denaturation at $94^{\circ} \mathrm{C}$ for $4 \mathrm{~min}$, denaturation at $94^{\circ} \mathrm{C}$ for $30 \mathrm{sec}$, annealing at $57^{\circ} \mathrm{C}$ for $30 \mathrm{sec}$, and extension at $72^{\circ} \mathrm{C}$ for $30 \mathrm{sec}$, with a total of 30 cycles. When the reaction was completed, the PCR base line substrates mode was selected for data analysis and correction. The $2^{-\Delta \Delta C t}$ method was conducted to compare relative expressions, and the formula was expressed as $\Delta \Delta \mathrm{Ct}=\Delta \mathrm{Ct}$ the model group $-\Delta \mathrm{Ct}$ the normal group' in which $\Delta \mathrm{Ct}=\mathrm{Ct}_{\text {target gene }}-\mathrm{Ct}_{\text {internal reference }}$ The relative expressions of target genes were equal to the value of $\Delta \Delta \mathrm{Ct}$.

\section{Western blot}

The total protein concentration was detected with the bicinchoninic acid (BCA) kit (Shanghai Yeasen Biotechnology Co., Ltd., China). Quantitation experiment was conducted based on different concentration. Briefly, the protein was separated with polyacrylamide gel, transferred onto polyvinylidene fluoride (PVDF) membranes, and sealed in 5\% BSA
Table 1. Primer sequences for RT-qPCR. Note: RT-qPCR, reverse transcription quantitative polymerase chain reaction; IRF7, interferon regulatory factors 7; AFAP1-AS1, actin filamentassociated protein 1 antisense RNA 1; RIG-1, retinoid-inducible protein 1; MDA5, melanoma differentiation-associated gene 5; LGP2, laboratory of genetics and physiology 2; Bcl-2, B cell lymphoma 2; GAPDH, glyceraldehyde-3phosphate dehydrogenase; F, forward; R, reverse

\begin{tabular}{lc}
\hline Genes & Primer sequences \\
\hline \multirow{2}{*}{ IRF7 } & F: 5'GAGAAGAGCCTGGTCCTGGT3' \\
& R: 5'CTAGGTCACTCGGCACAG3' \\
AFAP1-AS1 & F: 5'TCGCTCAATGGAGTGACGGCA3' \\
& R: 5'CGGCTGAGACCGCTGAGAACTT3' \\
RIG-1 & F: 5'GACTGGACGTGGCAAAACAA3' \\
& R: \\
MDA5 & 5'TTGAATGCATCCAATATACACTTCTG3' \\
& F: 5'TCGAATGGGTATTCCACAGACG3' \\
LGP2 & R: 5'GTGGCGACTGTCCTCTGAA3' \\
& F: 5'GGGCCTCCAAACTCGATGG3' \\
Bcl-2 & R: 5'TTCTGGGGTGACATGATGCAC3' \\
& F: 5'TTGGATCAGGGAGTTGGAAG3' \\
NF- $\kappa$ B & F: 5'TGTCCCTACCAACCAGAAGG3' \\
& R: 5'CCAGGTTCTGGAAACTGTGGAT3' \\
TNF- $\alpha$ & F: 5'TGCTTGTTCCTCAGCCTCTT3' \\
& R: 5'AGATGATCTGACTGCCTGGG3' \\
GAPDH & F: 5'-GGGAAGGTGAAGGTCGGAGTC-3' \\
& R: 5'-CAGCCTTGACGGTGCCATG-3' \\
\hline
\end{tabular}

was in room temperature for $1 \mathrm{~h}$. The membrane was incubated with the addition of primary antibodies i.e. rabbit anti- interferon regulatory factor (IRF)7 (1:1000, Abcam, UK), rabbit anti-p-IRF7 (1:1000, Abcam, UK), rabbit anti-retinoid-inducible protein (RIG)-1 (1:1000, Abcam, UK), rabbit anti-MDA5 (1:50000, Abcam, UK), rabbit anti-LGP2 (1:1000, Abcam, UK), rabbit antiBcl-2 (1:50000, Abcam, UK), rabbit anti-NF-кB (1:50000, Abcam, UK), rabbit anti-TNF- $\alpha$ (1:50000, Abcam, $\mathrm{UK})$ and rabbit anti- $\beta$-actin $(1: 1000, \mathrm{Abcam}, \mathrm{UK})$ at $4^{\circ} \mathrm{C}$ overnight. After rinsed 3 times in Tris-buffered saline plus $0.1 \%$ Tween 20 (TBST) ( 5 min per rinse), the membrane was incubated at room temperature for $1 \mathrm{hr}$ with horseradish peroxidase-labeled goat anti-rabbit IgG secondary antibody (1: 20000, Abcam, UK). After that, the membrane was re-washed with TBST for three times ( 5 min per washing). Films were developed and photographed by a gel imaging apparatus (Gel Doc XR, Bio-Rad, US). The relative expression of proteins was presented by the ratio of gray value between the target protein and reference value.

\section{3-(4, 5-dimethyl-2-thiazolyl)-2, 5-diphenyl-2-H-tetrazolium bromide (MTT) assay}

Cells were harvested for the MTT assay. Single cell suspension was seeded into a 96-well plate with $6 \mathrm{X}$ $10^{3}$ cells $/ 0.2 \mathrm{ml}$ in each well. Each well was added with $20 \mu \mathrm{L}$ MTT solution $(5 \mathrm{mg} / \mathrm{mL}$, Guduo Biotechnology Company, China), and incubated for $2 \mathrm{hrs}$ at $37^{\circ} \mathrm{C}$. After the supernatants were removed, $150 \mu \mathrm{L}$ of dimethyl sulfoxide (DMSO) solution was added into each well. Subsequently, the optical density (OD) value at 570 $\mathrm{nm}$ of each well was measured using a microplate reader (Tecan, Switzerland). The cell viability curve was drawn by using the OD values as ordinates.

\section{5-ethynyl-2'-deoxyuridine (EdU) staining}

When the cell growth density reached $80 \%, 0.25 \%$ trypsin was used to digest cells to single cell suspension. The EdU experiment was performed based on the instructions from the EdU kit manufacturer (Sigma, US). Immunofluorescence assay was used to detect the DNA synthesis. After infection $24 \mathrm{hrs}$, a total of $50 \mu \mathrm{mol} / \mathrm{L} \mathrm{EdU}$ culture solutions were replaced and incubated for $48 \mathrm{hrs}$, fixed in $4 \%$ polyoxymethylene for $15 \mathrm{~min}$, and then the cells were incubated with $0.2 \%$ glycine for $10 \mathrm{~min}$, and washed by PBS twice. 


\section{Cellular Physiology Cell Physiol Biochem 2018;50:179-195

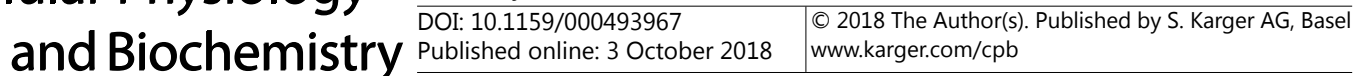

Tang et al.: AFAP1-AS1 in NSCLC

Hoechest was used to incubate cells in the dark for 10 min and 0.5\% Triton X-100 was used to wash cells for 3 times, and then the results were observed immediately under a fluorescence microscope (Olympus, Japan).

Transwell assay

Capacity of cancer cell invasion was assessed by using the Transwell Cell Culture Inserts (BD Biosciences, US) in 24-well plates. A total of 1 X $10^{5}$ cells in $100 \mu \mathrm{l}$ of serum-free RPMI 1640 medium were added to the top chamber. The bottom well contained growth medium with $20 \%$ FBS. Cells were incubated for $36 \mathrm{hrs}$ at $37^{\circ} \mathrm{C}$, and then, the cells that had invaded through the filter pores were fixed with methanol, stained with hematoxylin and observed under a inverted microscope (Olympus, Japan). The number of invasive cells were counted from 5 randomly selected $20 \mathrm{X}$ fields for each experiment and averaged.

\section{Statistics}

Data were presented as mean values \pm standard deviations (SD). The Statistical Program for Social Sciences (SPSS) 21.0 software (SPSS, IBM, US) was used for data analysis. The one-way analysis of variance (ANOVA) and the Kruskal-Wallis test were used to compare values among groups followed by the Student's t-test or the Mann-Whitney U-test to compare values between groups. The Tukey-Kramer test or the Steel test was also used depending on the distribution of data. The Pearson correlation analysis was carried out for the analysis of the correlation of two variable quantities. All tests were two-tailed, with the level of significance set to $P<0.05$.

\section{Results}

Highly expressed AFAP1-AS1 was identified in patients with NSCLC

Over-expressed AFAP1-AS1 in NSCLC (Fig. 1A) was found by the analysis of the gene expression profile GSE33532. Therefore, AFAP1-AS1 was selected for this study. As predicted by the MEM (Multi Experiment Matrix) website, IRF7 is the target gene of AFAP1-AS1 by involving in the regulation of RIG-I-like receptor signaling pathway (Fig. 1B). The RNA22 website (https://cm.jefferson.edu/rna22) further verified the binding sites of IRF7 and AFAP1-AS1 (Fig. 1C).

RT-qPCR was performed to test the expression of AFAP1-AS1 in the serum of patients with NSCLC, benign lung tumor and healthy controls. The relative expressions of AFAP1-AS1 in the peripheral serum of NSCLC patients and benign lung tumor patients are significantly higher than that of healthy controls $(p<0.05)$. Compared with benign lung tumor, the relative expression of AFAP1-AS1 in NSCLC was remarkably increased (all $p<0.05$ ) (Fig. 2). Taken together, AFAP1-AS1 was significantly up-regulated in patients with NSCLC.

Alterations of Tregs, Th1, Th2, regulatory B cells and dendritic cells in NSCLC, benign tumor and normal subjects

Next, the immune cell subsets such as peripheral blood Tregs, Th1, Th2, regulatory B cells and dendritic cells were detected by flow cytometry. The percentage of $\mathrm{CD}^{+} \mathrm{T}$ cells in the normal control group was higher than that in the benign and NSCLC groups, while the $\mathrm{CD} 4{ }^{+} \mathrm{T}$ cells and Th1 in the normal control group were in an opposite trend (all $p<0.05$ ). The percentage of $\mathrm{CD} 8^{+} \mathrm{T}$ cells in the normal control group was lower than that in the benign and NSCLC group $(p<0.05)$. The content of Th2 in the normal control group was higher than that of the NSCLC group $(p<0.05)$.

According to the molecular markers of the $\mathrm{B}$ cell surface, the $\mathrm{B}$ cells were divided into naive $B$ cells $\left(\mathrm{CD} 19^{+} \mathrm{IgM}^{+}\right)$, memory B cells $\left(\mathrm{CD} 19^{+} \mathrm{CD} 27^{+}\right)$and mature $\mathrm{B}$ cells $\left(\mathrm{CD} 19^{+} \mathrm{CD} 38^{+}\right)$. The experimental results show that the proportion of $\mathrm{CD}^{1} 9^{+} \mathrm{IgM}^{+}$naive $\mathrm{B}$ cells and $\mathrm{CD} 19^{+} \mathrm{CD} 27^{+}$memory B cells in the NSCLC group and benign tumor group were increased in the peripheral blood $(p<0.05)$. NSCLC group and benign tumor group had declined CD19+ CD38 ${ }^{+}$mature B cells, CD80, CD83 and CD1a in peripheral blood $(p<0.05)$, CD1a, CD80, CD83 


\begin{tabular}{|c|c|c|}
\hline Cellular Physiology & Cell Physiol Biochem 2018;5c & $0: 179-195$ \\
\hline and $\mathrm{Bi}$ & $\begin{array}{l}\text { Dol: } 10.1159 / 000493967 \\
\text {, Publisned onilne; October } 2018\end{array}$ & $\begin{array}{l}\text { O } 2018 \text { The Author(s). Published by S. Karger AG, Basel } \\
\text { www.karger.com/cpb }\end{array}$ \\
\hline
\end{tabular}

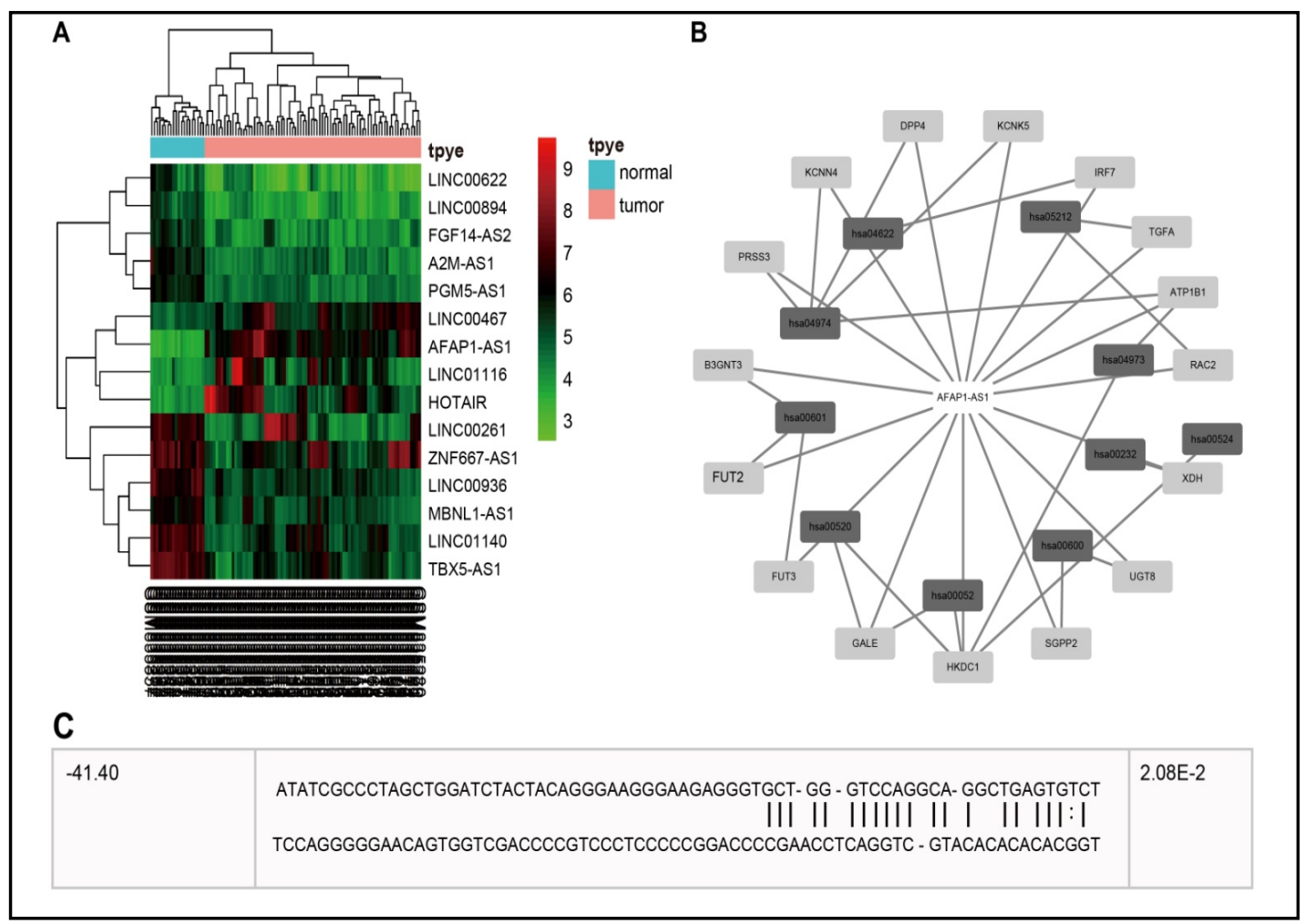

Fig. 1. Bioinformatics prediction. Over-expressed AFAP1-AS1 in NSCLC was found by the analysis of the gene expression profile GSE33532; the heat maps of AFAP1-AS1 for differentially expressed genes in the expression profile of GSE33532 (Fig. 1A). Based on the MEM analysis, IRF7 is the target gene of AFAP1AS1 by involving in the regulation of RIG-I-like receptor signaling pathway was predicted by the MEM (Multi Experiment Matrix) website (Fig. 1B). The RNA22 website (https://cm.jefferson.edu/rna22) further verified the binding sites of IRF7 and AFAP1-AS1 (Fig. 1C). MEM, Multi-Experiment Matrix; AFAAP1-AS1, actin filament-associated protein 1 antisense RNA 1; IRF7, interferon regulatory factor 7.

Fig. 2. Expression of AFAP1-AS1 was increased in NSCLC. RT-qPCR was performed to test the expression of AFAP1AS1 in the serum of patients with NSCLC, benign lung tumor and healthy controls. The relative expression of AFAP1-AS1 in the peripheral serum of NSCLC patients and benign lung tumor patients is significantly higher than that of healthy controls. Compared with benign lung tumor, the relative expression of AFAP1-AS1 in NSCLC was remarkably increased (all $\mathrm{p}<0.05$ ). Data are presented as mean \pm standard deviation (SD). $\mathrm{n}=173$ in the normal group, $\mathrm{n}=118$ in the benign tumor group, and $\mathrm{n}=165$ in the NSCLC group. ${ }^{*}, \mathrm{p}<0.05$ compared with the normal

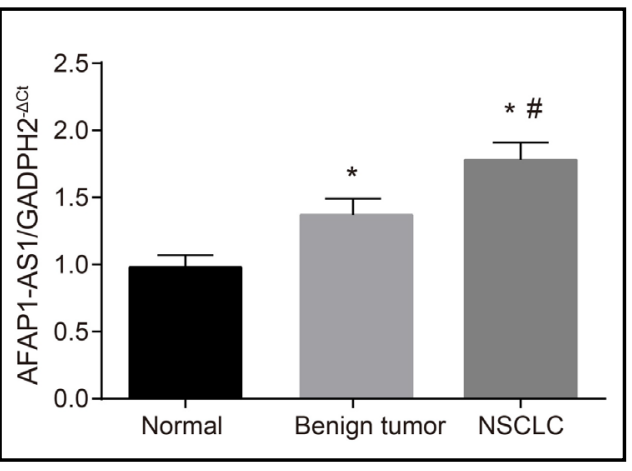
group; \#, $\mathrm{p}<0.05$ compared with the benign tumor group; AFAAP1-AS1, actin filament-associated protein 1 antisense RNA 1. NSCLC, non-small cell lung cancer; GAPDH, glyceraldehyde-3-phosphate dehydrogenase.

had significant difference among groups $(p<0.05)$ while CD86 showed no notable difference in blood ( $p>0.05)$ (Fig. 3).

Decreased levels of IL-12 and increased levels of IL-10 and IFN- $\gamma$ in NSCLC

ELISA was performed to detect the levels of IL-10, IL-12, and IFN- $\gamma$. Results showed that the expression level of IL-10 was significantly higher in the benign tumor group and 


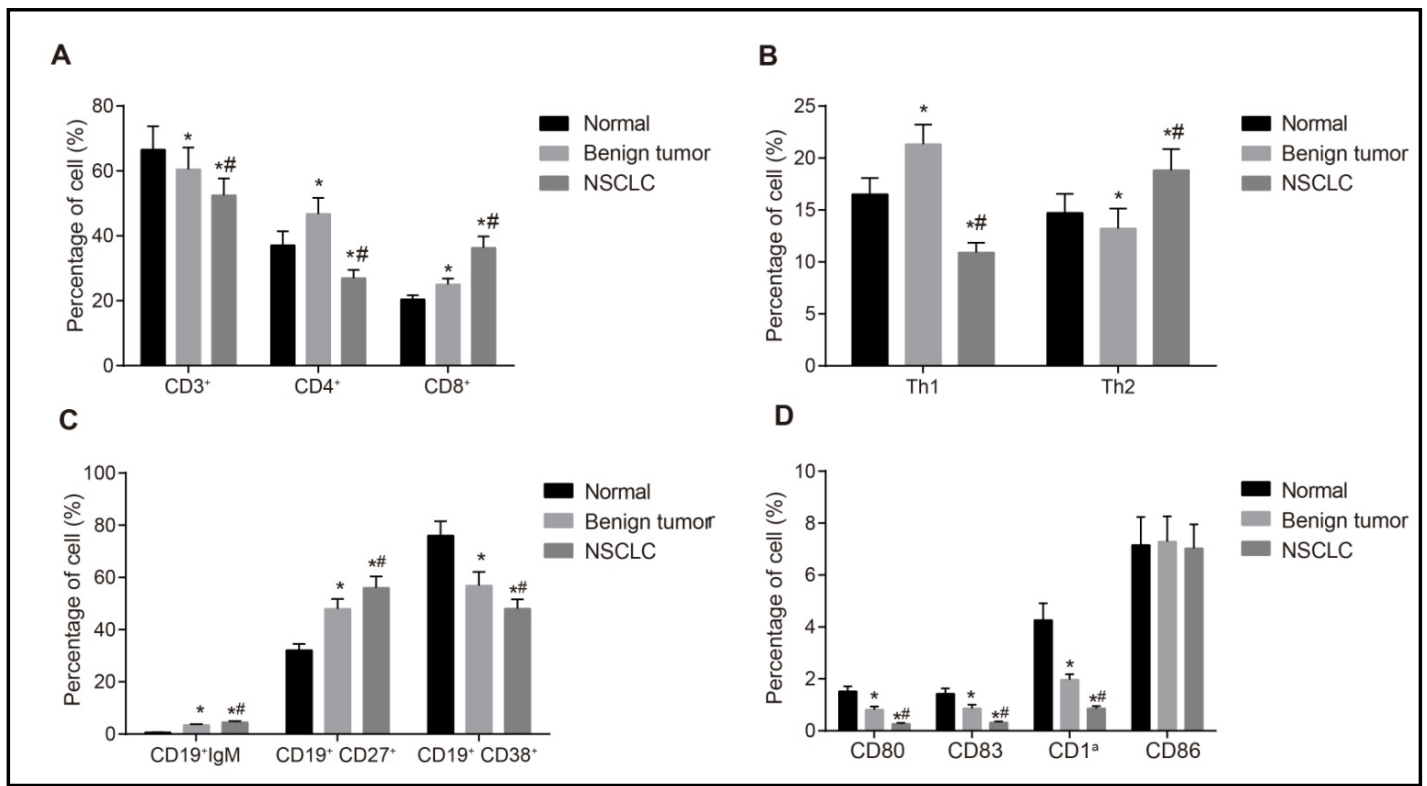

Fig. 3. Immune cell subsets in the peripheral blood of patients with NSCLC. Flow cytometry was used to identify the changes of the immune cell subsets in the peripheral blood of patients with NSCLC. The percentage of $\mathrm{CD}^{+} \mathrm{T}$ cells in the normal control group was higher than that in the benign and NSCLC groups; the $\mathrm{CD} 4{ }^{+} \mathrm{T}$ cells and $\mathrm{Th} 1$ in the normal control group were in an opposite trend (all $\mathrm{p}<0.05$ ); the percentage of $\mathrm{CD}^{+} \mathrm{T}$ cells in the normal control group was lower than that in the benign and NSCLC group $(\mathrm{p}<0.05)$ (Fig. 3A). The content of Th2 in the normal control group was higher than that of the NSCLC group ( $p<0.05$, Fig. 3B). According to the molecular markers of the B cell surface, the B cells were divided into naive B cells $\left(\mathrm{CD} 19^{+} \operatorname{IgM}{ }^{+}\right)$, memory B cells $\left(\mathrm{CD} 19^{+} \mathrm{CD} 27^{+}\right)$and mature B cells $\left(\mathrm{CD} 19^{+} \mathrm{CD} 38^{+}\right)$. The experimental results show that the proportion of $\mathrm{CD}_{19}{ }^{+} \mathrm{IgM}^{+}$naive $\mathrm{B}$ cells and $\mathrm{CD} 19^{+} \mathrm{CD} 27^{+}$memory B cells in the NSCLC group and benign tumor group were increased in the peripheral blood $(\mathrm{p}<0.05$, Fig. 3C). NSCLC group and benign tumor group had declined expressions of CD19+ CD38+mature B cells, CD80, CD83 and CD1a in peripheral blood cells $(\mathrm{p}<0.05)$, expressions of CD1a, CD80 and CD83 were significantly different among groups $(\mathrm{p}<0.05)$, while CD86 showed no notable difference in blood ( $p>0.05$, Fig. 3D). Data are presented as mean \pm standard deviation (SD). $n=173$ in the normal group, $n=118$ in the benign tumor group, $n=165$ in the NSCLC group. *, $\mathrm{p}<0.05$ compared with the normal group;, p $<0.05$ compared with the benign tumor group. NSCLC, non-small cell lung cancer.

the NSCLC group, and the NSCLC group was higher than the benign tumor group $(p<0.05)$. The level of IL12 in the NSCLC group was significantly lower than that of the normal control group and the benign tumor group; the IL-12 level in the benign tumor group was lower than that in the normal group. The level of IFN- $\gamma$ in NSCLC group was significantly higher than that of the normal control group and the benign tumor group ( $p<0.05)$ (Table 2$)$. All data indicate higher levels of IL-12, IL-10 and lower level of IFN- $\gamma$ in NSCLC.
Table 2. ELISA detection for the levels of IL-12, IFN- $\gamma$ and IL-10 in peripheral blood. Note: NSCLC, non-small cell lung cancer; ELISA, enzyme-linked immunosorbent assay. Data are measurement data, expressed by means \pm standard deviation and analyzed by one way ANOVA from three independent experiments. $\mathrm{n}=173$ in the normal group, $\mathrm{n}=118$ in the benign tumor group, $\mathrm{n}=165$ in the NSCLC group. *, $p<0.05$ compared with the normal group;, , $<0.05$ compared with the benign tumor group; IL-12; interleukin 12; IL-10, interleukin; IFN- $\gamma$, interferon $\gamma$

\begin{tabular}{lccc}
\hline Biomarkers & Normal & Benign tumor & NSCLC \\
\hline IL-12 (ng/mL) & $43.52 \pm 3.67$ & $40.78 \pm 4.56^{*}$ & $25.43 \pm 2.68^{* \#}$ \\
IFN- $\gamma(\mathrm{ng} / \mathrm{L})$ & $3.86 \pm 0.46$ & $5.25 \pm 0.49^{*}$ & $8.12 \pm 1.06^{* \#}$ \\
$\mathrm{IL}-10(\mathrm{pg} / \mathrm{mL})$ & $21.37 \pm 1.63$ & $29.4 \pm 2.90^{*}$ & $41.52 \pm 4.57^{* \#}$ \\
\hline
\end{tabular}


Over-expression of AFAP1AS1 associated with NSCLC progression

Abnormal expression of AFAP1-AS1 was closely related to pathological grade, TNM staging and metastatic potential $(p<0.05)$ (Table 3) while not related to NSCLC type $(p>0.05)$. Compared with TNM stage I + II patients, the expression of AFAP1-AS1 mRNA in the TNM stage III + IV was significantly increased $(p<0.05)$. However, insignificant difference was see between TNM stage I and II patients, or between TNM stage III and IV patients. All data indicate that abnormal expression o AFAP1AS1 is closely related to pathological grade, TNM staging and metastatic potentials of NSCLC.
Table 3. Correlation between the expressions of IncRNA AFAP1-AS1 and the clinical characteristics of NSCLC. Note: TNM, tumor node metastasis; NSCLC, non-small cell lung cancer. Data are measurement data from three independent experiments. $\mathrm{n}=173$ in the normal group, $\mathrm{n}=118$ in the benign tumor group, $\mathrm{n}=165$ in the NSCLC group. In terms of the correlation of parameters of NSCLC with AFAP1-AS1, the comparison inside the group was analyzed by paired t test

\begin{tabular}{lcccc}
\hline Characteristics & $\mathrm{n}$ & AFAP1-AS1 expression & $\mathrm{t} / \mathrm{F}$ & $\mathrm{p}$ \\
\hline Histology & & & 0.564 & 0.574 \\
Squamous cell carcinoma & 75 & $1.77 \pm 0.21$ & & \\
Adenocarcinoma & 90 & $1.79 \pm 0.24$ & & \\
P-TNM stage & & & $16.920<0.001$ \\
I + II & $75+35$ & $1.62 \pm 0.15$ & & \\
III + IV & $30+25$ & $2.03 \pm 0.14$ & \\
Differentiation grade & & & $29.060<0.001$ \\
G1 & 48 & $1.94 \pm 0.23$ & \\
G2 & 54 & $1.79 \pm 0.19$ & \\
G3 & 63 & $1.65 \pm 0.18$ & \\
Lymph node metastasis & & & $16.030<0.001$ \\
Yes & 60 & $2.02 \pm 0.14$ & & \\
No & 105 & $1.64 \pm 0.15$ & & \\
\hline
\end{tabular}

Successful tranfection of siRNA against AFAP1-AS1 and AFAP1-AS1over-expressing vector siRNA1 with the best interference effect in 3 kinds of siRNA-AFAP1-AS1 for subsequent transfection experiments are shown in Fig. 4A. The expression of AFAP1-AS1 was significantly higher in the AFAP1-AS1 vector group, and lower in the siRNA-AFAP1-AS1 group than the NC group (both $p<0.05$ ) (Fig. 4B). The results show that transfections of over-expressed plasmids and siRNA were successful.

NSCLC cell line H1975 presented with the highest AFAP1-AS1 expression

RT-qPCR was used to select the cell line with the highest expression of AFAP1-AS1 from NSCLC cell lines (A549, H1975, H1650, H1395, and H1299). Results showed that compared with other four cells, the expression of AFAP1-AS1 was the highest in H1975 cells (Fig. 5).

Effects of AFAP1-AS1 on the mRNA and protein expression of related genes

To investigate the mechanisms and functions of AFAP1-AS1, IRF7 and RIG-I-like receptor signaling pathway in NSCLC, their expressions were measured in transfected cells in vivo, by using RT-qPCR and Western blot. Compared with the blank and the NC groups, the expressions of mRNA (Fig. 6A) and (phosphorylation) protein (Fig. 6B) of IRF7, RIG1, MDA5, LGP2, Bcl-2, NF- $\kappa \mathrm{B}$, and TNF- $\alpha$ were up-regulated in the AFAP1-AS1 vector group, while down-regulated in the siRNA-AFAP1-AS1 group. The expressions of mRNA (Fig. 6A) and (phosphorylation) protein (Fig. 6B) of RIG-1, MDA5, LGP2, Bcl-2, NF-кB, and TNF- $\alpha$ were significantly down-regulated in the RNF5 group as compared with the blank and the NC groups (all $p<0.05$ ) (Fig. 6A). No difference in IRF7, AFAP1-AS1 mRNA and (phosphorylation) protein expression level was seen between the RNF5 and NC groups ( $p>$ 0.05). The expression of signal pathway related genes in the AFAP1-AS1 Vector+ RNF5 group was insignificantly different from that of the blank group and the NC group $(p>0.05)$ (Fig. 6). All data suggest that up-regulated AFAP1-AS1 could activate IRF7, the RIG-I-like receptor signaling pathway, and Bcl-2, etc.. 


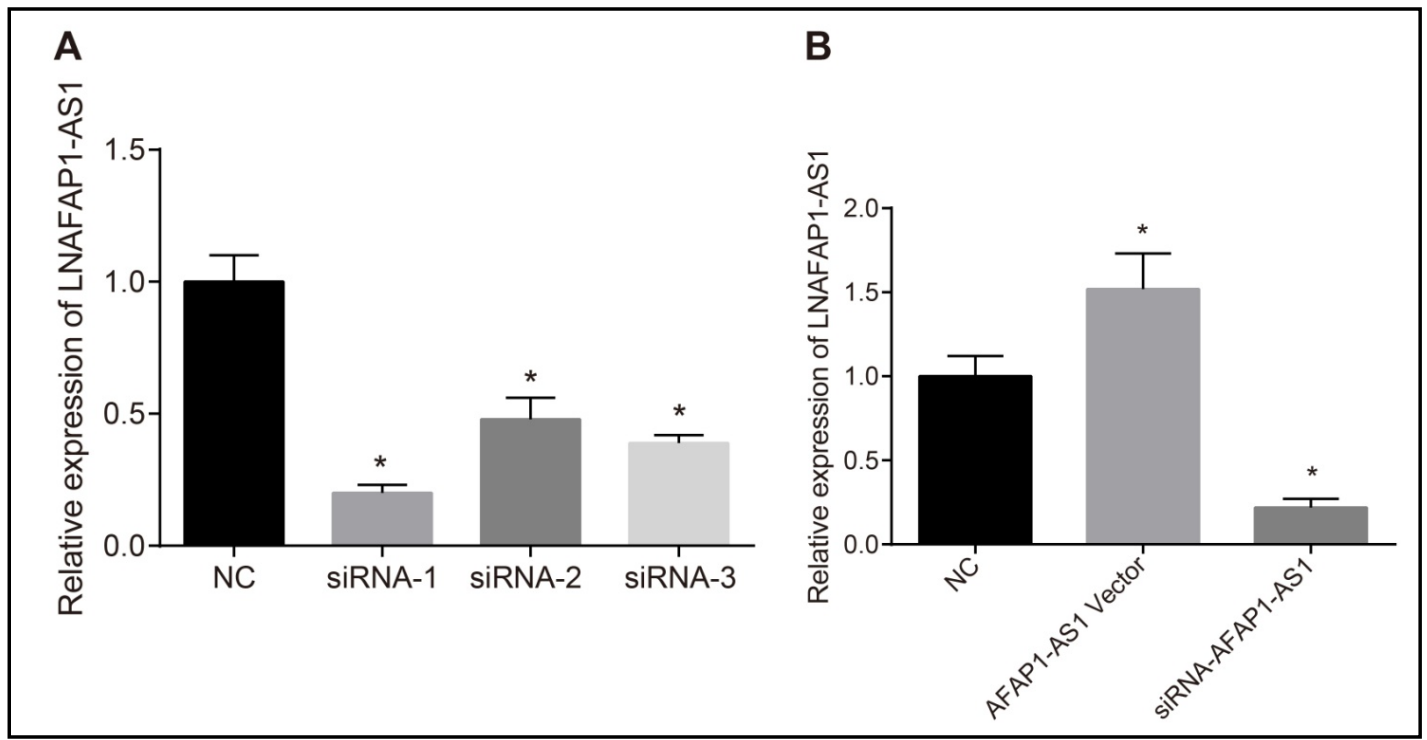

Fig. 4. The verification of the efficiency of siRNA against AFAP1-AS1 and the vector over-expressing AFAP1-AS1 by RT-qPCR. siRNA1 that showed the best interference effect in 3 kinds of siRNA-AFAP1-AS1 for subsequent transfection experiments are shown in Fig. 4A. The expression of AFAP1-AS1 was significantly higher in the AFAP1-AS1 vector group, and lower in the siRNA-AFAP1-AS1 group, than in the NC group (both $\mathrm{p}<0.05$, Fig. 4B). Data are presented as mean \pm standard deviation (SD) of one representative out of three independent experiments. *, p<0.05 compared with the NC group; NC, negative control.

Fig. 5. NSCLC cell line screening for the highest expression of AFAP1-AS1. RT-qPCR was used to select the cell line with the highest expression of AFAP1AS1 from NSCLC cell lines (A549, H1975, H1650, H1395, and H1299). Results of the RT-qPCR experiment showed that compared with other four cell lines, the expression of AFAP1-AS1 was the highest in H1975 cells (Fig. 5). Data are presented as mean \pm standard deviation (SD) of one representative out of three independent experiments.

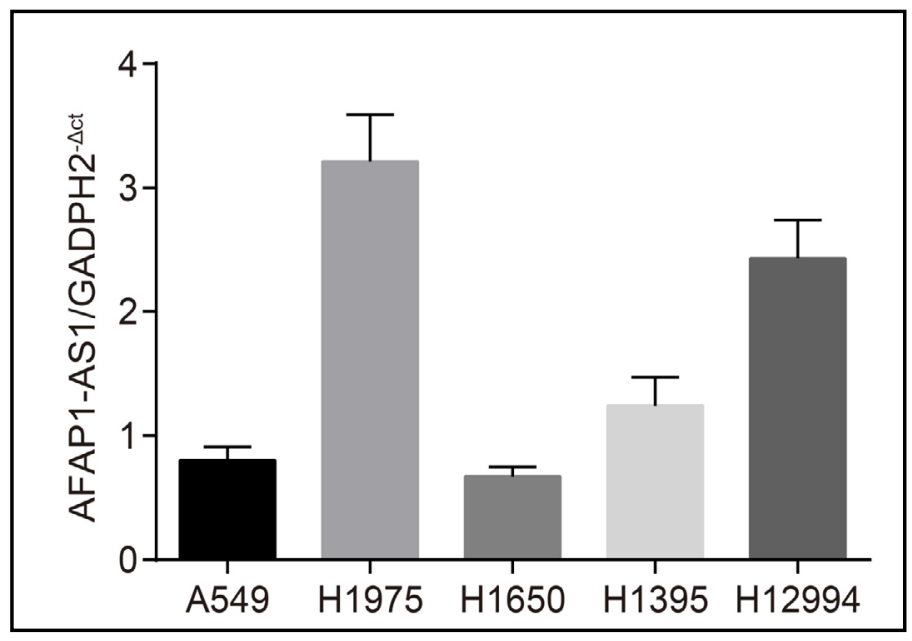

Over-expression of AFAP1-AS1 promoted NSCLC cell proliferation

We investigated the ability of AFAP1-AS1 to influence the biological functions of NSCLC cells. Positive cell rate from MTT and EdU experiments represented the proliferation rate. No difference in cell proliferation was seen among groups at $24 \mathrm{hrs}$. At $48 \mathrm{hrs}$ and $72 \mathrm{hrs}$, cell viability was increased in the AFAP1-AS1 vector group, but decreased in the siRNA-AFAP1AS1 and RIG-I-like receptor signaling pathway inhibitor (RNF5) groups (all $p<0.05$ ). Taken together, these results suggest that AFAP1-AS1 could promote cell proliferation of NSCLC (Fig. 7). 


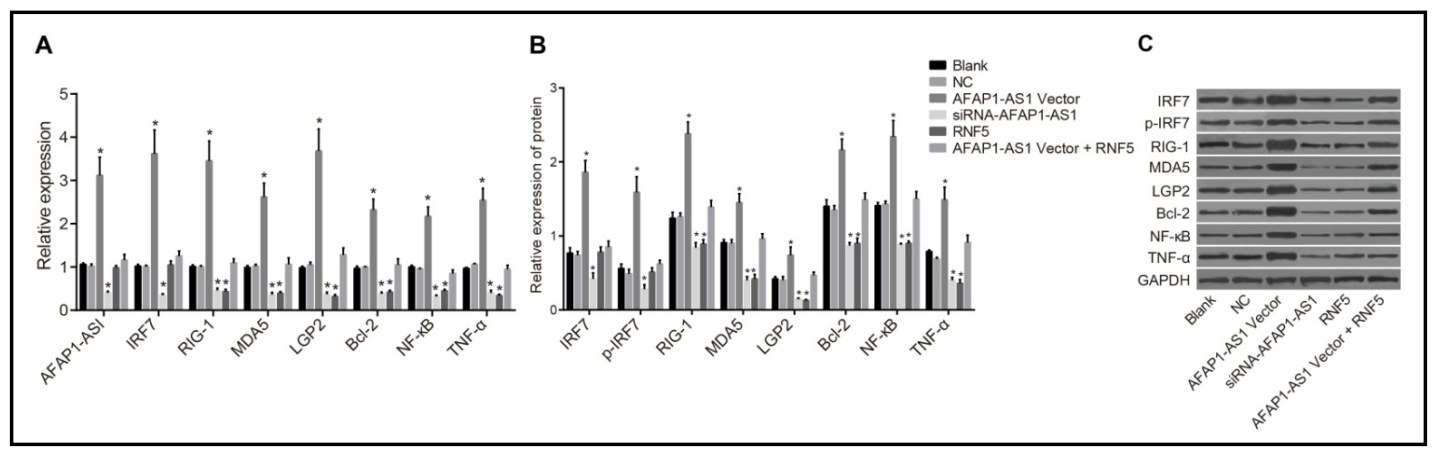

Fig. 6. The effect of AFAP1-AS1 on the mRNA and protein expression of related genes detected by RT-qPCR and Western blot analysis. To investigate the mechanisms and functions of AFAP1-AS1, IRF7 and RIG-I-like receptor signaling pathway in NSCLC, their expressions were measured in transfected cells in vivo, by using RT-qPCR and Western blot. Compared with the blank and the NC groups, the expressions of mRNA (Fig. 6A) and (phosphorylation) protein (Fig. 6B) of IRF7, RIG-1, MDA5, LGP2, Bcl-2, NF- $\mathrm{BB}$, and TNF- $\alpha$ were up-regulated in the AFAP1-AS1 vector group, while down-regulated in the siRNA-AFAP1-AS1 group. The expressions of mRNA (Fig. 6A) and (phosphorylation) protein (Fig. 6B) of RIG-1, MDA5, LGP2, Bcl-2, NF$\kappa B$, and TNF- $\alpha$ were significantly down-regulated in the RNF5 group as compared with the blank and the NC groups (all p<0.05) (Fig. 6A). No difference in IRF7, AFAP1-AS1 mRNA and (phosphorylation) protein expression level was seen between the RNF5 and NC groups ( $p>0.05)$. The expression of signal pathway related genes in the AFAP1-AS1 Vector+ RNF5 group was insignificantly different from that of the blank group and the NC group ( $p>0.05)$. A, the mRNA expression of related genes in transfected cells; $B$, the protein expression of related genes in transfected cells, $\mathrm{C}$, protein bands detected by western blot. Data are presented as mean \pm standard deviation (SD) of one representative out of three independent experiments. *, p $<0.05$ compared with the blank and NC groups. RT-qPCR, reverse transcription-quantitative polymerase chain reaction; AFAAP1-AS1, actin filament-associated protein 1 antisense RNA 1; IRF7, interferon regulatory factor 7. Bcl-2, B cell lymphoma 2; GAPDH, glyceraldehyde-3-phosphate dehydrogenase; RIG-1, retinoidinducible protein 1; MDA5, melanoma differentiation-associated gene 5; LGP2, laboratory of genetics and physiology 2.

\section{Over-expression of AFAP1-AS1 promoted NSCLC cell invasion and migration}

We further studied the effect of AFAP1-AS1 on NSCLC cell migration by using the Transwell assay. The increment in migrated cell number after 24-hr incubation was not obvious, and the cell proliferation between controls and the AFAP1-AS1 vector group did not reach significant difference at $36 \mathrm{~h}$. Therefore, we detected the cell invasion and migration after 36-hr incubation. Compared with the blank and the NC groups, cell migration and invasion were enhanced in the AFAP1-AS1 vector group while weakened in the siRNAAFAP1-AS1 and RNF5 groups $(p<0.05)$. There was no significant difference among the blank, the NC, and the AFAP1-AS1 vector+ RNF5 groups $(p>0.05)$. These results suggest that AFAP1-AS1 could promote NSCLC cell migration and invasion by activating RIG-I-like receptor signaling pathway (Fig. 8).

\section{Over-expression of AFAP1-AS1 inhibited NSCLC cell apoptosis}

Lastly, we evaluated the effects of AFAP1-AS1 on NSCLC cell cycle and apoptosis by using flow cytometry. Annexin $\mathrm{V}^{+} \mathrm{PI}{ }^{-}$cells represent apoptotic cells. Result shows that there was no significant difference in apoptosis rate between the blank and the NC groups $(p>$ 0.05). Compared with the blank and NC groups, the apoptosis rate was decreased in the AFAP1-AS1 vector group ( $p<0.05)$, increased in the siRNA-AFAP1-AS1 group and the RNF5 group $(p<0.05)$; while the AFAP1-AS1 vector+RNF5 group had no significant change $(p>$ 0.05). These results indicate that AFAP1-AS1 could inhibit cell apoptosis (Fig. 9A, 9B). The cell proportions of G0/G1 phase cells in the blank, the NC, the AFAP1-AS1 vector, the siRNAAFAP1-AS1, the RNF5, and the AFAP1-AS1 vector+RNF5 groups were $67 \% \pm 7 \%, 65 \% \pm 6 \%$, $47 \% \pm 5 \%, 82 \% \pm 9 \%, 80 \% \pm 8 \%, 66 \% \pm 7 \%$, respectively. Proportions of cells during the $\mathrm{S}$ 


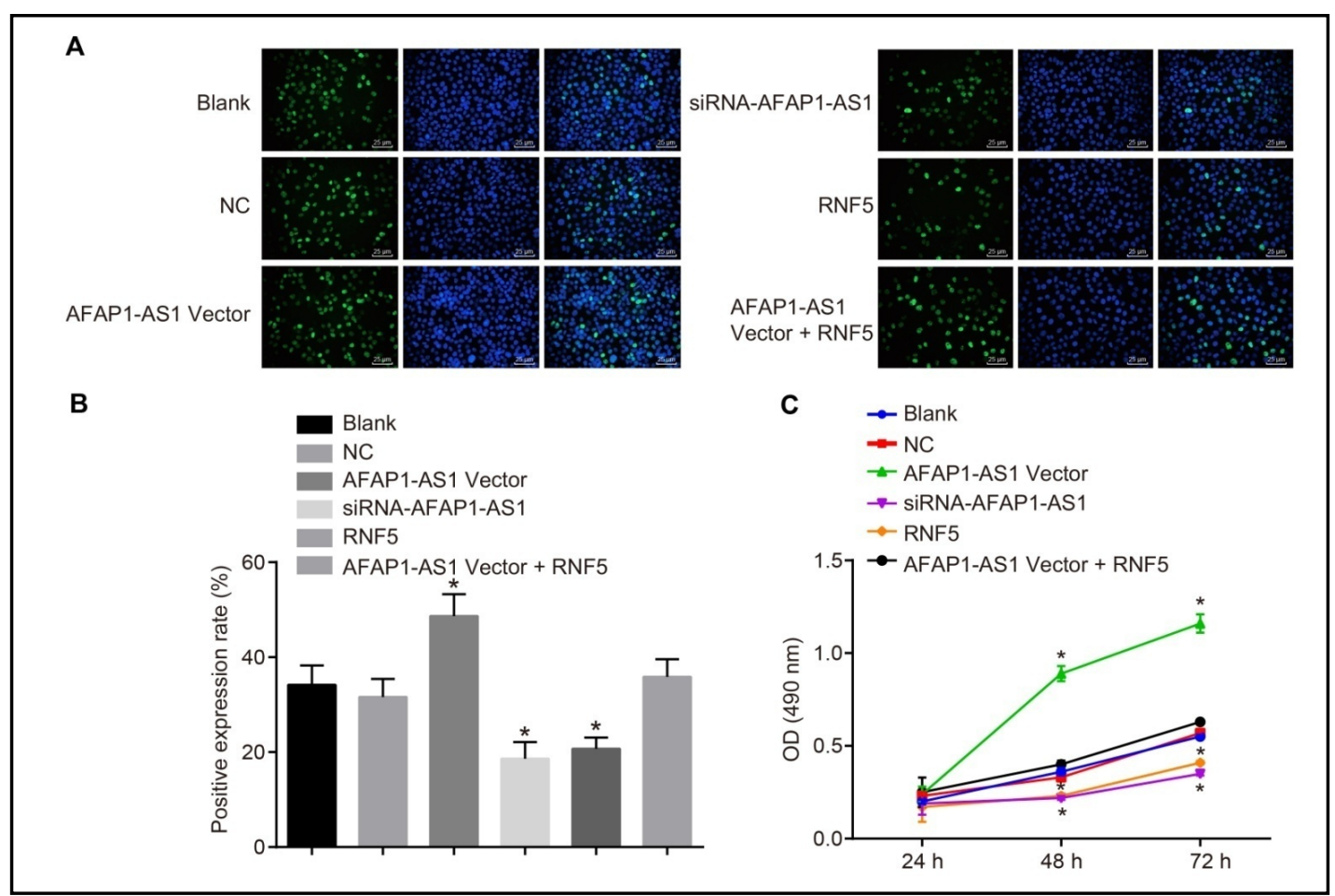

Fig. 7. EdU staining and MTT assay indicated the promotion effect of AFAP1-AS1 on NSCLC cell proliferation. The ability of AFAP1-AS1 to influence the biological functions of NSCLC cells was investigated. The positive cell rate represented the proliferation rate. Compared with the blank and NC groups, insignificant difference was seen in cell proliferation among groups at $24 \mathrm{hrs}$. At $48 \mathrm{hrs}$ and $72 \mathrm{hrs}$, cell viability was increased in the AFAP1-AS1 vector group, but decreased in the siRNA-AFAP1-AS1 and RIG-I-like receptor signaling pathway inhibitor (RNF5) groups (all p<0.05). A, the immunofluorescence analysis of positive cells following EdU staining, B, the quantification analysis for EdU positive cells; C, MTT assay to detect the cell viability. These results suggest that AFAP1-AS1 could promote cell proliferation of NSCLC. Data are presented as mean \pm standard deviation (SD) of one representative out of three independent experiments. ${ }^{*}, \mathrm{p}<0.05$ compared with the blank and NC groups; NC, negative control.

phase were $21 \% \pm 3 \%, 24 \% \pm 3 \%, 39 \% \pm 4 \%, 4 \% \pm 1 \%, 8 \% \pm 1 \%, 23 \% \pm 2 \%$, respectively. There was no significant difference between the blank and the NC groups $(p>0.05)$. Compared with the blank and the NC groups, the siRNA-AFAP1-AS1 and RNF5 showed prolonged G0/ G1 phase (increased cell ratio) and shortened S phase (decreased of cell proportion) (all $p<0.05)$. Insignificant difference in the $\mathrm{G} 2$ phase was seen among groups $(p>0.05)$ (Fig. 9C, 9D). All data revealed that up-regulated AFAP1-AS1 could shorten the G0/G1 phase and inhibit NSCLC cell apoptosis. 


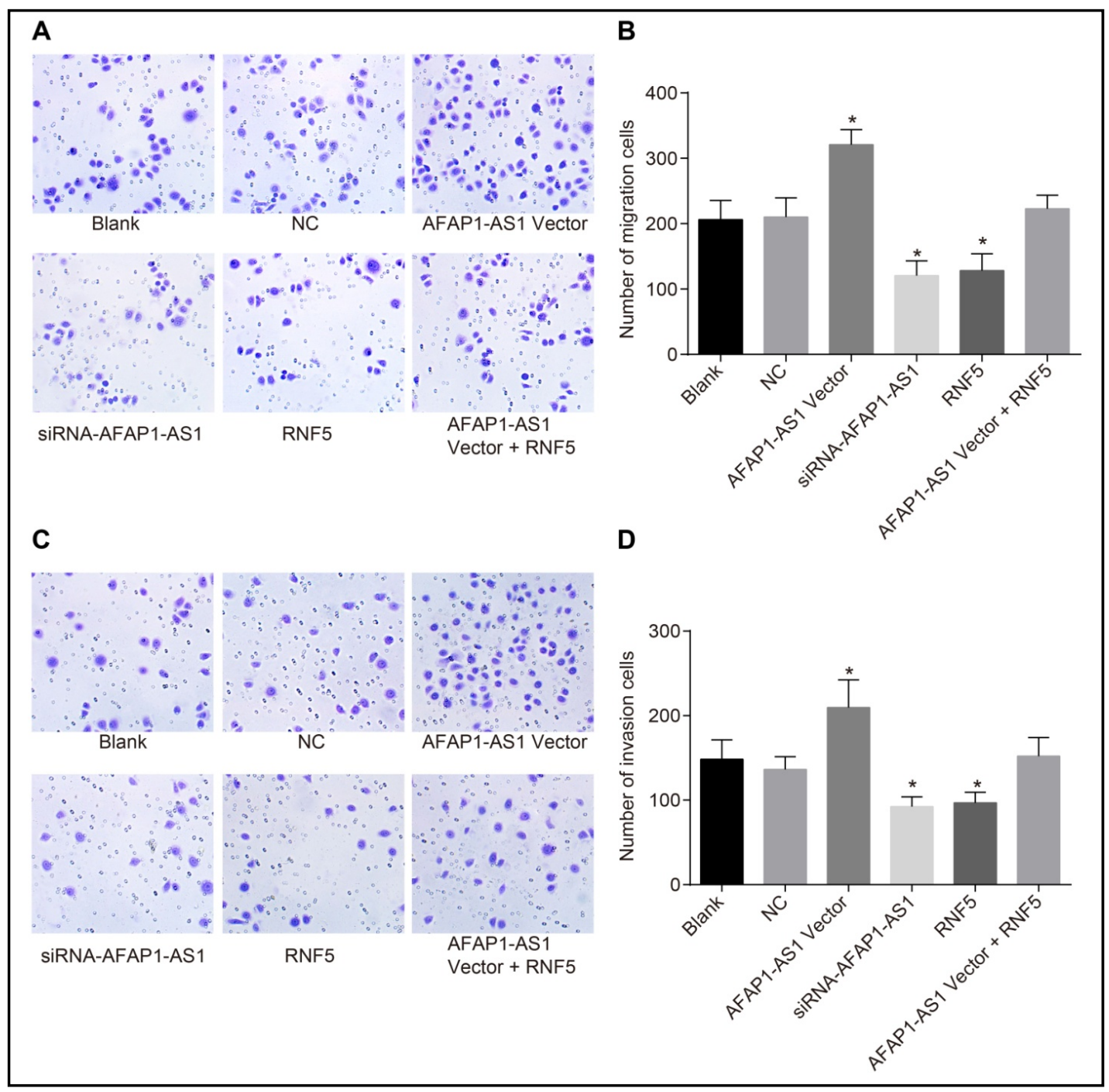

Fig. 8. The Transwell migration and invasion assays indicated the promotion effect of AFAP1-AS1 on NSCLC cell migration and invasion. The effect of AFAP1-AS1 on NSCLC cell migration was evaluated by using the Transwell assay. Compared with the blank and the NC groups, cell migration and invasion were enhanced in the AFAP1-AS1 vector group while weakened in the siRNA-AFAP1-AS1 and RNF5 groups ( $<<0.05)$. There was no significant difference among the blank, the NC, and the AFAP1-AS1 vector+ RNF5 groups ( $p>0.05$ ). $A$, the migrating cells observed under the microscope. Higher staining intensity reflected more migrated cells; $\mathrm{B}$, the quantification analysis for cell migration conditions; $\mathrm{C}$, the penetrating cells observed under the microscope. Higher staining intensity reflected more invaded cells. These results suggest that AFAP1AS1 could promote NSCLC cell migration and invasion by activating RIG-I-like receptor signaling pathway. Data are presented as mean \pm standard deviation (SD) of one representative out of three independent experiments. *, p<0.05 compared with the blank and NC groups; NC, negative control. 


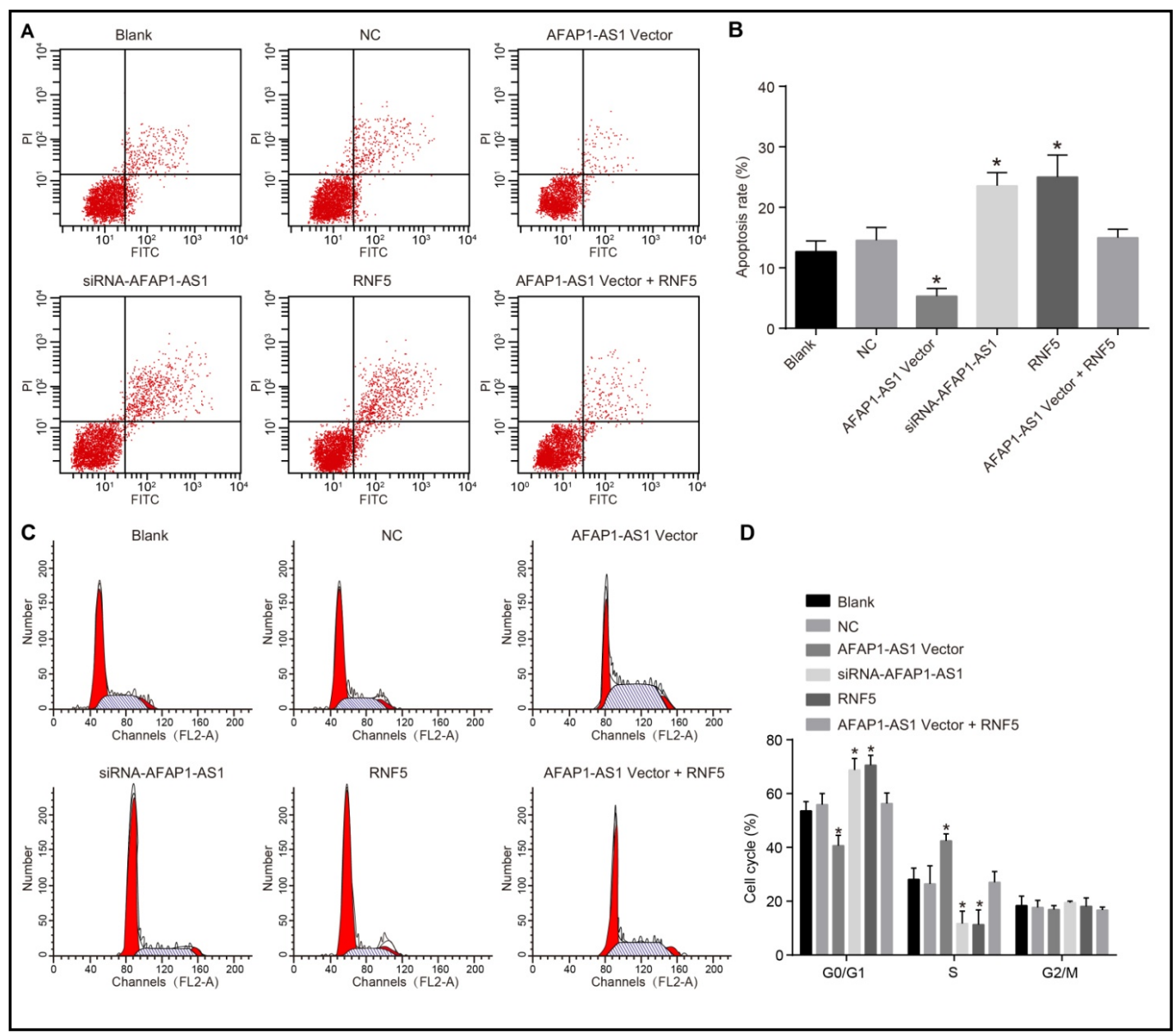

Fig. 9. Flow cytometric detection indicated that Up-regulated AFAP1-AS1 promoted NSCLC cell cycle progression and inhibited the apoptosis. Annexin $\mathrm{V}^{+} \mathrm{PI}^{-}$cells represent apoptotic cells. The effects of AFAP1AS1 on NSCLC cell cycle and apoptosis were evaluated by using flow cytometry. Result shows that there was no significant difference in apoptosis rate between the blank and the NC groups ( $p>0.05)$. Compared with the blank and the NC groups, the apoptosis rate was decreased in the AFAP1-AS1 vector group ( $p<0.05)$, increased in the siRNA-AFAP1-AS1 group and the RNF5 group $(\mathrm{p}<0.05)$; while the AFAP1-AS1 vector+RNF5 group had no significant change ( $\mathrm{p}>0.05)$. These results indicate that AFAP1-AS1 could inhibit cell apoptosis (Fig. 9A, 9B). The cell proportions of G0/G1 phase cells in the blank, the NC, the AFAP1-AS1 vector, the siRNA-AFAP1-AS1, the RNF5, and the AFAP1-AS1 vector+ RNF5 groups were $67 \% \pm 7 \%, 65 \% \pm 6 \%, 47 \% \pm 5 \%$, $82 \% \pm 9 \%, 80 \% \pm 8 \%, 66 \% \pm 7 \%$, respectively. Proportions of cells during the $\mathrm{S}$ phase were $21 \% \pm 3 \%$, $24 \% \pm 3 \%, 39 \% \pm 4 \%, 4 \% \pm 1 \%, 8 \% \pm 1 \%, 23 \% \pm 2 \%$, respectively. There was insignificant difference between the blank and the NC groups ( $\mathrm{p}>0.05)$. Compared with the blank and the NC groups, the siRNA-AFAP1-AS1 and RNF5 showed prolonged G0/G1 phase (increased cell ratio) and shortened S phase (decreased of cell proportion) (all $\mathrm{p}<0.05$ ) while the AFAP1-AS1 vector group was on the contrary. There was no significant difference in AFAP1-AS1 vector+ RNF5 group ( $p>0.05$ ). Insignificant difference was seen in the G2 phase among groups ( $p>0.05$ ) (Fig. 9C, 9D). All data revealed that up-regulated AFAP1-AS1 could inhibit NSCLC cell apoptosis. Data are presented as mean \pm standard deviation (SD) of one representative out of three independent experiments. *, p<0.05 compared with the blank and NC groups; NC, negative control. 


\section{Cellular Physiology Cell Physiol Biochem 2018;50:179-195 \\ \begin{tabular}{ll|l} 
and Biochemistry Published online: 3 October 2018 & $\begin{array}{l}\text { C } 2018 \text { The Author(s). Published by S. Karger AG, Basel } \\
\text { www.karger.com/cpb }\end{array}$
\end{tabular}}

Tang et al.: AFAP1-AS1 in NSCLC

\section{Discussion}

In this study, we first investigated the expressions of AFAP1-AS1 in patients with NSCLC and confirmed the up-regulation of AFAP1-AS1 in NSCLC. Aberrant expressions of AFAP1AS1 were associated with pathological grade, TNM staging and metastatic potential of NSCLC. We further selected an NSCLC cell line with the highest expression of AFAP1-AS1, i.e. the H1975 cell line for in vitro experiments. We found that AFAP1-AS1 could activate IRF7, the RIG-I-like receptor signaling pathway and Bcl-2, and AFAP1-AS1 could promote NSCLC cell proliferation, invasion and migration while inhibiting cell apoptosis.

AFAP1-AS1 has been associated with NSCLC in recent studies [18, 19]. Interestingly, down-regulation of AFAP1-AS1 could inhibit tumor cell growth and invasion in lung adenocarcinoma [20]. Initially, we found that AFAP1-AS1 was significantly up-regulated in patients with stage III-IV NSCLC with lymph node metastasis, indicating that AFAP1AS1 may play an important role in the initiation and progression of NSCLC. Our findings, alongside with those previous studies [18-20] consistent point to AFAP1-AS1 as a promising biomarker and therapeutic target of NSCLC.

Considering many potential targets governed by each single lncRNA, one challenge is to find the functional target of AFAP1-AS1 in NSCLC. We employed bioinformatics methods to indentify the IRF7 gene as the potential target gene of AFAP1-AS1. The mammalian IRF family of transcription factors comprises nine members: IRF1, IRF2, IRF3, IRF4, IRF5, IRF6, IRF7, IRF8 and IRF9. NF- $\kappa$ B is the prototypical transcription factor that has been extensively studied, and NF- $\mathrm{KB}$ is most important in the gene-regulatory networks in immune responses, including the induction of the genes that encode IFN- $\beta$ and pro-inflammatory cytokines. More recently, members of the IRF family of transcription factors have been shown to have markedly diverse roles in the gene-regulatory networks in the immune system. IRFs have recently attracted great attentions as they modulate cellular responses whereby influencing tumorigenesis [21]. In this context, the regulation of oncogenesis by IRFs may have important implications for understanding the role of lncRNAs in lung cancer. IRF7 has been shown to bear oncogenic properties in several malignancies [22]. More importantly, epigenetic silencing of IRF7 in vitro could lead to increased sensitivity of lung cancer cells to oncolytic viruses [23].

RIG-I-like receptors are cytosolic pattern-recognition receptors (PRRs) that recognize pathogen-associated molecular patterns and induce antiviral immune responses. Activation of newly synthesized IRF7, following recognition of viral nucleic acids by pattern PRRs, e.g. the RIG-I-like receptor pathway, leads to the expression of large amounts of IFN- $\beta$ and many of the IFN- $\alpha$ proteins [24]. Expression of the cytosolic RIG-I and MDA5 is also induced by type I IFNs, i.e. IFN- $\alpha$ and IFN- $\beta$, thereby contributing to the positive-feedback regulation [25].

We performed transfection of AFAP1-AS1 to see the changes of the expressions of IRF7 and the RIG-I-like receptor pathway related genes. Our results showed that IRF7, the RIG-I-like receptor pathway related genes (RIG-1, MDA5), LGP2, Bcl-2, NF- $\kappa$ B, and TNF- $\alpha$ could be up-regulated by over-expressing AFAP1-AS1. This effect was corroborated by using siRNA to silence the expression of AFAP1-AS1 after which expressions of IRF7, the RIG-Ilike receptor pathway related genes (RIG-1, MDA5), LGP2, Bcl-2, NF- $\kappa B$, and TNF- $\alpha$ were down-regulated. We further examined the effect of AFAP1-AS1 on NSCLC cell migration and invasion. Over-expression of AFAP1-AS1 could promote the migration and invasion of NSCLC cell and meanwhile inhibited the apoptosis of NSCLC cells. Similarly, this effect could reversed by siRNA silencing. Taken together, we demonstrated that lncRNA AFAP1AS1 promoted migration and invasion of non-small cell lung cancer via up-regulating IRF7 and the RIG-I-like receptor signaling pathway. AFAP1-AS1 may bind to IRF7 to activate the positive-feedback regulation loop of IFN signaling, followed by the activation of the RIG-Ilike receptor pathway as well as Bcl-2, leading to the development and progression of NSCLC.

We also explored the changes of immune cell subsets in the peripheral blood of patients with NSCLC. The percentages of $\mathrm{CD}^{+} \mathrm{T}, \mathrm{CD} 4^{+} \mathrm{T}$ and Th1 cells in the NSCLC groups were 
down-regulated while the percentage of $\mathrm{CD}^{+} \mathrm{T}$ and $\mathrm{Th} 2$ cells was up-regulated, indicating a protective role of $\mathrm{CD} 8^{+} \mathrm{T}$ and Th2 cells in NSCLC. Patients with NSCLC had more CD19 ${ }^{+} \mathrm{CD} 27^{+}$ $B$ cells and less CD19+CD38 ${ }^{+}$B cells and declined expressions of CD80, CD83 and CD1a in peripheral blood cells. In accordance to the changes of blood cell subsets, blood levels of IL-12 and IL-10 were elevated and IFN- $\gamma$ decreased in patients with NSCLC. Taken together, ratio of CD4/CD8 cells was decreased and ratios of Th1/Th2 cells and cytokines were also decreased in NSCLC.

\section{Conclusion}

In conclusion, we demonstrated the novel oncogenic lncRNA AFAP1-AS1 played a crucial role in the development and progression of NSCLC. AFAP1-AS1 promotes migration and invasion of non-small cell lung cancer via up-regulating IRF7 and the RIG-I-like receptor signaling pathway.

\section{Acknowledgements}

The study was supported by grants from Jilin University.

\section{Disclosure Statement}

The authors declare no potential conflicts of interest.

\section{References}

-1 Reck M, Rabe KF: Precision Diagnosis and Treatment for Advanced Non-Small-Cell Lung Cancer. N Engl J Med 2017;377:849-861.

-2 Herbst RS, Heymach JV, Lippman SM: Lung cancer: N Engl J Med 2008;359:1367-1380.

- 3 Mauguen A, Pignon J P, Burdett S, Domerg C, Fisher D, Paulus R, Mandrekar S J, Belani C P, Shepherd F A, Eisen T, Pang H, Collette L, Sause W T, Dahlberg S E, Crawford J, O’Brien M, Schild S E, Parmar M, Tierney J F, Le Pechoux C, Michiels S and Surrogate Lung Project Collaborative G: Surrogate endpoints for overall survival in chemotherapy and radiotherapy trials in operable and locally advanced lung cancer: a reanalysis of meta-analyses of individual patients' data. Lancet Oncol 2013;14:619-626. Siegel R, Naishadham D, Jemal A: Cancer statistics, 2012. Cancer J Clin 2010;62:10-29.

5 Hiley CT, Le Quesne J, Santis G, Sharpe R, de Castro DG, Middleton G, Swanton C: Challenges in molecular testing in non-small-cell lung cancer patients with advanced disease. Lancet 2016;388:1002-1011.

6 Kapranov P, Cheng J, Dike S, Nix DA, Duttagupta R, Willingham AT, Stadler PF, Hertel J, Hackermüller J, Hofacker IL, Bell I, Cheung E, Drenkow J, Dumais E, Patel S, Helt G, Ganesh M, Ghosh S, Piccolboni A, Sementchenko V et al.: RNA maps reveal new RNA classes and a possible function for pervasive transcription. Science 2007;316:1484-1488.

7 Ricciuti B, Mecca C, Crinò L, Baglivo S, Cenci M, Metro G: Non-coding RNAs in lung cancer. Oncoscience 2014;1:674-705.

-8 Gupta RA, Shah N, Wang KC, Kim J, Horlings HM, Wong DJ, Tsai MC, Hung T, Argani P, Rinn JL, Wang Y, Brzoska P, Kong B, Li R, West RB, van de Vijver MJ, Sukumar S, Chang HY: Long non-coding RNA HOTAIR reprograms chromatin state to promote cancer metastasis. Nature 2010;464:1071-1076.

-9 Gibb EA, Brown CJ, Lam WL: The functional role of long non-coding RNA in human carcinomas. Mol Cancer 2011;10:38.

10 Zhang F, Li J, Xiao H, Zou Y, Liu Y, Huang W: AFAP1-AS1: A novel oncogenic long non-coding RNA in human cancers. Cell Prolif 2018;51:e12397. 


\section{Cellular Physiology Cell Physiol Biochem 2018;50:179-195 \begin{tabular}{ll|l} 
DOI: 10.1159/000493967 & $\begin{array}{l}\text { O 2018 The Author(s). Published by S. Karger AG, Basel } \\
\text { www.karger.com/cpb }\end{array}$
\end{tabular} \\ Tang et al.: AFAP1-AS1 in NSCLC}

11 Zeng Z, Bo H, Gong Z, Lian Y, Li X, Li X, Zhang W, Deng H, Zhou M, Peng S, Li G, Xiong W: AFAP1-AS1, a long noncoding RNA upregulated in lung cancer and promotes invasion and metastasis. Tumour Biol 2016;37:729-737.

12 Yu H, Xu Q Liu F, Ye X, Wang J, Meng X: Identification and validation of long noncoding RNA biomarkers in human non-small-cell lung carcinomas. J Thorac Oncol 2015;10:645-654.

13 Fujita A, Sato JR, Rodrigues Lde O, Ferreira CE, Sogayar MC: Evaluating different methods of microarray data normalization. BMC Bioinformatics 2006;7:469.

14 Smyth GK: Linear models and empirical bayes methods for assessing differential expression in microarray experiments. Stat Appl Genet Mol Biol 2004;3:3.

15 Adler P, Kolde R, Kull M, Tkachenko A, Peterson H, Reimand J, Vilo J: Mining for coexpression across hundreds of datasets using novel rank aggregation and visualization methods. Genome Biol. 2009;10:139.

16 Wang J, Duncan D, Shi Z, Zhang B: WEB-based GEne SeT AnaLysis Toolkit (WebGestalt): update 2013. Nucleic Acids Res 2013;41:77-83.

17 Zhong B, Zhang L, Lei C, Li Y, Mao AP, Yang Y, Wang YY, Zhang XL, Shu HB: The ubiquitin ligase RNF5 regulates antiviral responses by mediating degradation of the adaptor protein MITA. Immunity 2009;30:397-407.

18 Deng J, Liang Y, Liu C, He S, Wang S: The up-regulation of long non-coding RNA AFAP1-AS1 is associated with the poor prognosis of NSCLC patients. Biomed Pharmacother 2015;75:8-11.

19 Li W, Li N, Kang X, Shi K: Circulating long non-coding RNA AFAP1-AS1 is a potential diagnostic biomarker for non-small cell lung cancer. Clin Chim Acta 2017;475:152-156.

20 Zhuang Y, Jiang H, Li H, Dai J, Liu Y, Li Y, Miao L, Cai H, Xiao Y, Xia H, Wang Y, Shi M: Down-regulation of long non-coding RNA AFAP1-AS1 inhibits tumor cell growth and invasion in lung adenocarcinoma. Am J Transl Res 2017;9:2997-3005.

-21 Yanai H, Negishi H, Taniguchi T: The IRF family of transcription factors: Inception, impact and implications in oncogenesis. Oncoimmunology 2012;1:1376-1386.

22 Kondo S, Endo K, Wakisaka N, Aga M, Kano M, Seishima N, Imoto T, Kobayashi E, Moriyama-Kita M, Nakanishi Y, Murono S, Pagano JS, Yoshizaki T: Expression of interferon regulatory factor 7 correlates with the expression of Epstein-Barr Virus latent membrane protein 1 and cervical lymph node metastasis in nasopharyngeal cancer. Pathol Int 2017;67:461-466.

-23 Li Q Tainsky MA: Epigenetic silencing of IRF7 and/or IRF5 in lung cancer cells leads to increased sensitivity to oncolytic viruses. PLoS One 2011;6:e28683.

-24 Yoshino H, Iwabuchi M, Kazama Y, Furukawa M, Kashiwakura I: Effects of retinoic acid-inducible gene-I-like receptors activations and ionizing radiation cotreatment on cytotoxicity against human non-small cell lung cancer in. Oncol Lett 2018;15:4697-4705.

25 Honda K, Taniguchi T:IRFs: master regulators of signalling by Toll-like receptors and cytosolic patternrecognition receptors. Nat Rev Immunol 2006;6:644-658. 